\title{
A Parking Management System Based on Embedded System for Stereo Garage
}

\author{
Yang Beiping, Shen Hongming, Han Lele, Yang Yongjie *
}

School of Electronics and Information ,Nantong University ,Nantong, Jiangsu 226019, China

e-mail: yangbeiping@163.com,e-mail: shen.hm@ntu.edu.cn, e-mail: hanlele@ntu.edu.cn

*corresponding author, e-mail: yang.yj@ntu.edu.cn

\section{Keywords: ARM; Embedded System; RFID Technology; Parking Management System}

\begin{abstract}
A parking management system based on embedded system and GSM network for stereo garage is proposed to solve the current parking problems in the cities. This system, using an ARM processor, advanced RFID and GSM communication technology, achieves effective automation management of the stereo garage. Moreover, an optimal parking strategy is analyzed and selected to reduce the waiting time to take the car.
\end{abstract}

\section{Introduction}

Since the 21st century, with the continued rapid growth of the national economy and people's income and consumption levels rising, the automobile industry developed rapidly, private car ownership rose quickly, the pressure on the city parking is increasing, parking difficulty has become an increasingly prominent social contradictions, seriously affects the daily lives of the general public, which restricts the development of society. Because of its small size, space utilization, investment, simple operation stereo garage gradually becomes the preferred solution to ease city parking difficulty [1]. The development and innovation of parking management technology for stereo garage can provide technical support for time charge, standardized management and so on, so the information and intelligence of parking management technology for stereo garage has become an urgent requirement to resolve the current plight of parking difficulty in the cities [2]. This article will use the embedded system, the radio frequency identification technology, combined with 485 and GSM technology [3, 4], presents a technologically advanced, reliable performance, highly automated intelligent parking management system.

\section{System Functions}

The whole system consists of the GSM communication module, keyboard module, 485 communications module, LCD display module, the ID /IC card reader module, status indication module and some other parts. The control system can correctly and quickly read information stored in the ID/IC card, reliably and stably communicate with Omron PLC, and control mechanical operation to realize vehicle access through PLC. The system block diagram is showed in Fig. 1. 


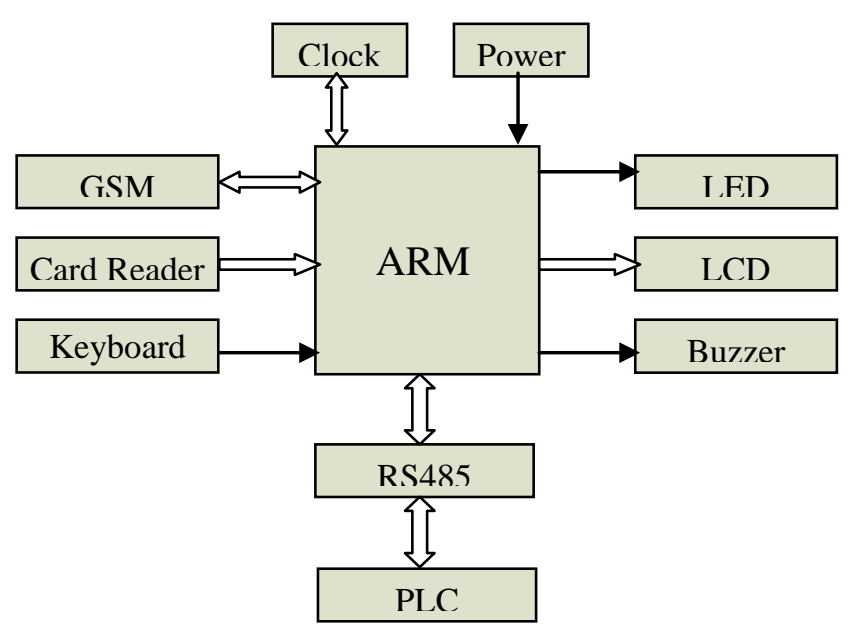

Figure 1. The block diagram of the system.

\section{Hardware Design}

A.

Power Module

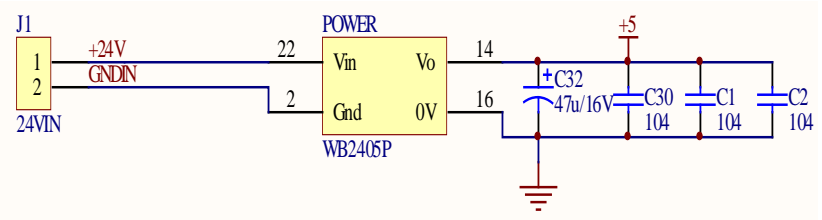

Figure 2. Schematic diagram of power module

Adopt $24 \mathrm{~V}$ to $5 \mathrm{~V}$ isolated power module WB2405P-1W5. It has a $1500 \mathrm{~V}$ isolation, wide input, stable output, low ripple, reliability and some other advantages. The $24 \mathrm{~V}$ input is provided by an external power. The power supply module can output an isolated, stable $5 \mathrm{~V}$ voltage. The principle is showed in Fig. 2.

\section{B. $\quad 485$ Communication Module}

Adopt MAX485 chip, combined with the protection of the peripheral circuit, and achieve the communication between control system and PLC. MAX485 is a low-power transceiver used for RS485 and RS-422 communication. Each device contains one driver and one receiver.Drivers are shortcircuit current limited, and are protected against excessive power dissipation by thermal shutdown circuitry that places their outputs into a high-impedance state. The receiver input has a fail-safe feature that guarantees a logic-high output if the input is open circuit. Transient protection bidirectional diode P6KE6.8ca is used to absorb the surge in the bus transmission process, prevent overvoltage. Resistors R1 and R2 keep the bus voltage in the correct range. R3 is a terminal resistor. R4 and R5 are current-limiting resistors which are used to prevent the bus short circuit or high current burning the chip. RXD, TXD and RDE signals are controlled by microcontroller port. A, B interface is the communication port of 485 interface. The principle is showed in Fig. 3.

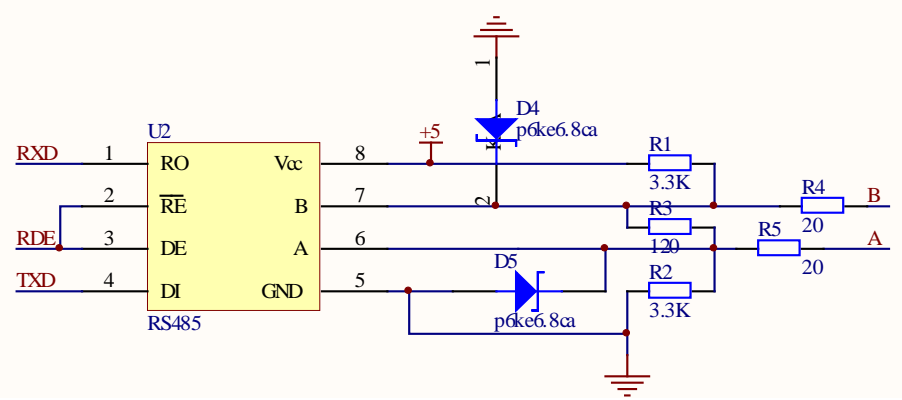

Figure 3. Schematic diagram of the communication module 


\section{C. $\quad$ Card Reading Module}

Adopt contactless IC reader MFRC522. The MFRC522 is a highly integrated transmission module for contactless communication at $13.56 \mathrm{MHz}$ [5]. This transmission module utilizes an outstanding modulation and demodulation concept completely integrated for different kinds of contactless communication methods and protocols at $13.56 \mathrm{MHz}$. When a card approaches the module, the module will output the card number in Wigand way, and then the user just need read the information simply. This card reader fully supports each MIFARE card and the operation of its compatible cards. It is very suitable for application of access control and attendance system. The distance which the reader can read the cards is far (according to the application it can reach 60-120 $\mathrm{mm}$ ). The reader can detect cards automatically, and it will actively send card information when a card is detected. The principle is showed in Fig. 4.
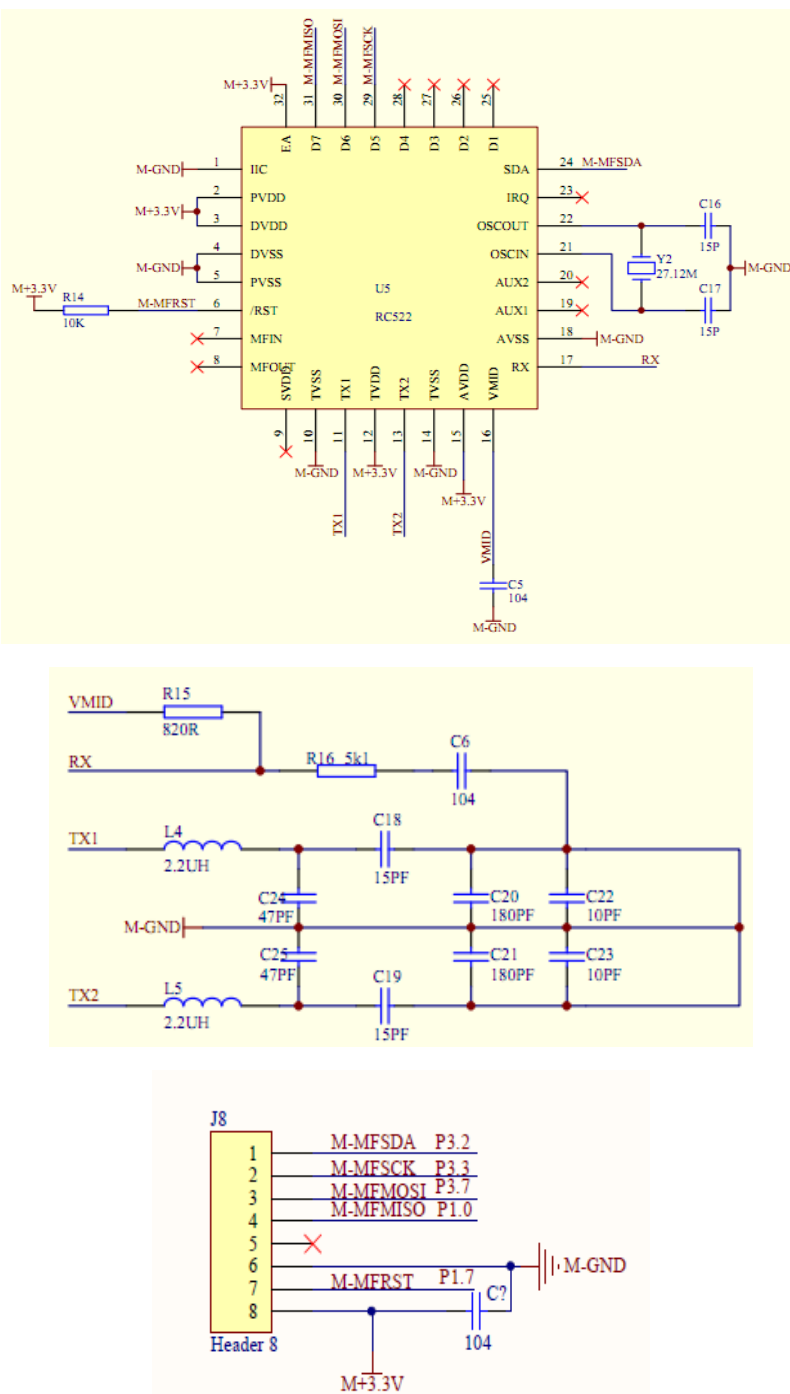

Figure 4. Schematic diagram of the card reading module 


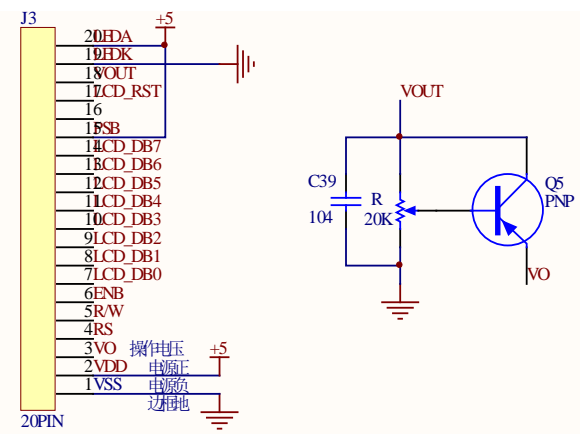

Figure 5. Schematic diagram of LCD display module

Adopt 128×64 liquid crystal display module. It can display Chinese characters and graphics, built in 8192 Chinese characters $(16 \times 16$ matrix) and 128 characters $(8 \times 16$ matrix $)$ and $64 \times 256$ dot matrix display RAM (GDRAM). The bias voltage circuit composed of PNP transistors can effectively control the changes of display contrast when the environment temperature changes. The circuit and interface is showed in Fig. 5.

\section{E. $\quad$ Prompt Module}

The circuit is showed in Fig. 6. This part is composed of a buzzer alarm circuit and a lightemitting diode lamp circuit. The circuit composed of triode and buzzer is controlled by output LSB1 signal of the ARM microprocessor. D0, D1 and D2 are three light-emitting diode indicators. The ARM microprocessor controls them to turn on or off.

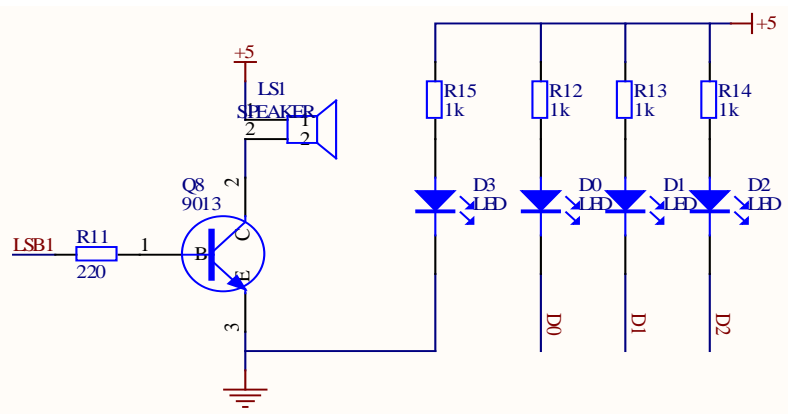

Figure 6. Prompting module circuit diagram

\section{F. $\quad$ ARM Microprocessor}

The ARM processor is the first RISC microprocessor that Acorn Computer Company limited designed for low budget market. It has small size, low power consumption, low cost, high performance, support Thumb (16-bit) / ARM (32-bit) dual instruction set and can be well compatible with 8/16-bit devices. This system adopts STM32F103 series MCU. STM32F103 series MCU is a high-density performance line ARM-based 32-bit MCU with 256-to- 512KB Flash, USB, CAN, 11 timers, 3 ADCs, 13 communication interfaces. It has low power consumption, fast operation, a variety of external equipment and some other advantages.

\section{G. GSM Network Module}

The expected time to pick up the car that the car owner entered through the keyboard before parking the car may change, therefore we will connect GSM module to the ARM microprocessor and apply internet technology to vehicle access. GSM (Global System for Mobile Communication) network technology is the most technologically mature and perfect system of the current mobile communication system based on TDMA (time division multiple access, divided into nonoverlapping time periods (frame), then the frame divided into non-overlapping time slot (channel) and has a one-to-one relationship with the users, distinguish signals from different address of the 
users based on the time slot to complete multiple connection.). GSM wireless communication module is proposed to adopt TC35i unit. The ARM processor is the first RISC microprocessor.

\section{Vehicle Access Process}

H. $\quad$ Parking Process

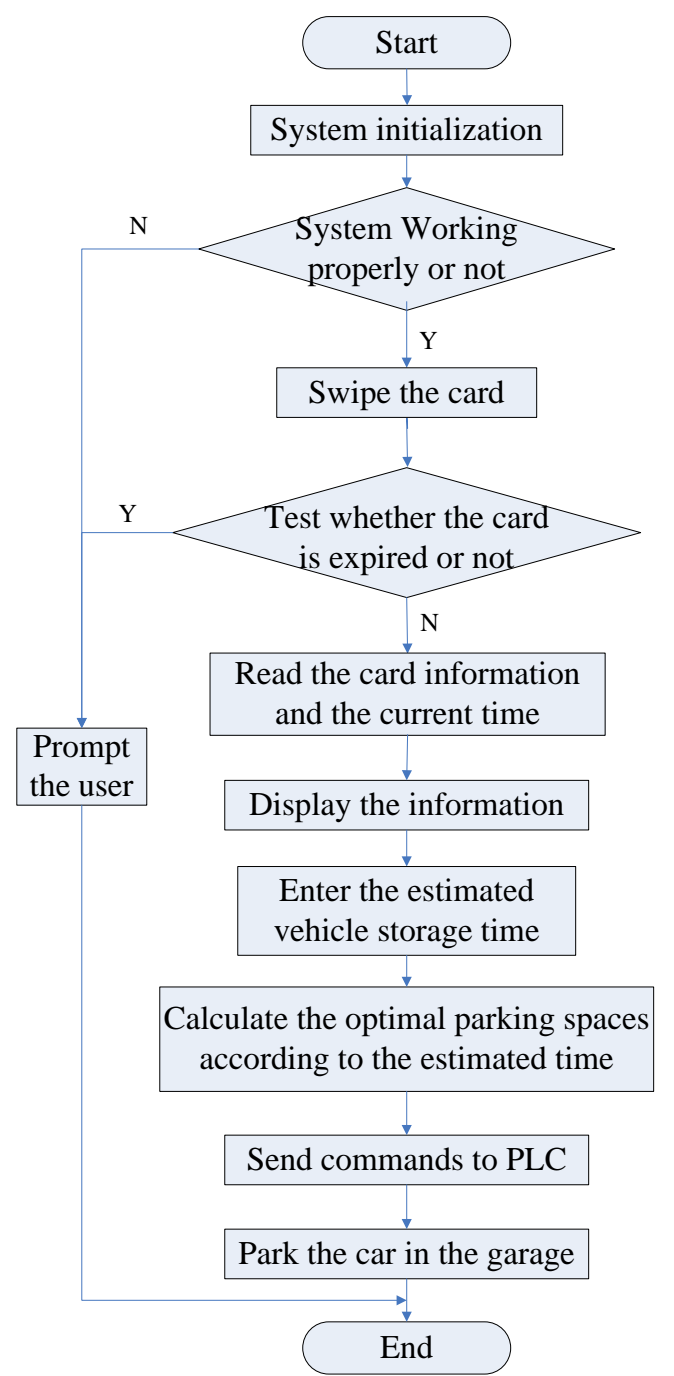

Figure 7. Flow chart of parking the car

From the practical point of view, to reduce the customers' waiting time to take the cars is a matter of priority. We will use the following structure: according to the expected time to pick up the car that the car owner entered through the keyboard before parking the car, use idle time of the garage equipment to do self-adjustment for the vehicles in the garage to increase the average work efficiency of the garage. Once free, the system will automatically move the cars which will be picked up first to the parking spaces nearer the entrance, the cars which need to be stored for a long time will be adjusted to the high area of parking places, meanwhile make some parking places in the low areas near the entrance free again in order to improve the optimum utilization of regional rate and greatly reducing the customers' waiting time to get the cars. The flow chart of parking the car is shown as Fig. 7.

I. $\quad$ Taking Process

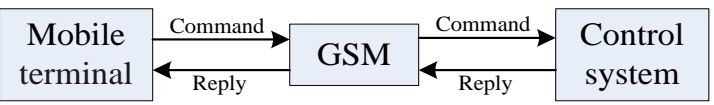

Figure.8. Schematic diagram of GSM communication 


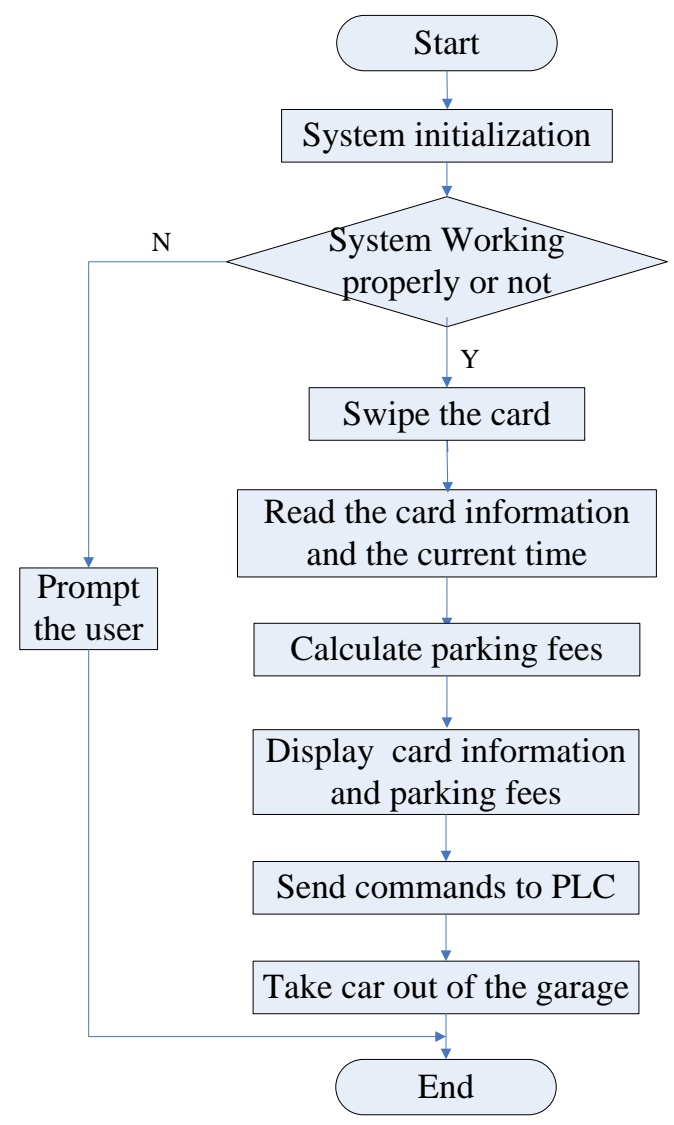

Figure.9. Flow chart of taking the car

Owners of the cars can use mobile phones to send command messages about to take the car through GSM network communication module before picking up the car. After receiving the short message from the mobile phone, the GSM network and ARM microprocessor will calculate out the time needed to move out the car and reply in the form of short message to the mobile terminal through GSM network communication module (Fig.8.). Through the short message reply, the owner can know when he can go downstairs to pick up the car and avoid long time waiting at the gate of the garage. The flow chart of taking the car is shown as Fig. 9.

\section{Conclusion}

Stereo garage has begun to spread in China because of the advantages like small size, space utilization, investment, simple operation and so on. The popularity of stereo garage and improved the situation of domestic spaces tense. With the rapid development of information technology, intelligent management of stereo garage will become the future development trend. In this article, we design an intelligent parking management system based on embedded system and GSM network for stereo garage. It can not only ease the difficult parking situation but also achieve automatic management. And, this intelligent parking management system can reduce the users' waiting time to take the cars with optimal parking strategy and GSM communication technology. It is convenient for owner to enter the expected time to pick up the car and know when he can go downstairs to take the car, which will avoid long time waiting at the gate of the garage. It has wide application prospect in modern smart traffic system.

Acknowledgment

This work was partly supported by the Gazelle Training plan projects of Nantong under Grant AA2014013 and the graduate student practice innovation training projects of Jiangsu Province under Grant CXLX13_873 and Nantong University under Grant YKC13005. 


\section{References}

[1] T. Dusan and L. Panta, “Intelligent parking systems,” European Journal of Operational Research, vol.175, Dec. 2006, pp. 1666-1681, doi: 10.1016/j.ejor.2005.02.033.

[2] M. Wada, K. S. Yoon and H. Hashimoto, "Development of advanced parking assistance system,” IEEE Transactions on Industrial Electronics, vol. 50, Feb. 2003, pp. 4-17, doi: 10.1109/tie.2002.807690.

[3] A. Munoz and J. A. Botia,, "Developing an intelligent parking management application based on multi-agent systems and semantic web technologies," Lecture Notes in Computer Science , vol. 6076, Jun. 2010, pp. 55-59, doi: 10.1007/978-3-642-13769-3_8.

[4] A. Razinkova, C. H. Chan and T. J. Hong, “An Intelligent Auto Parking System for Vehicles,” International Journal of Fuzzy Logic and Intelligent Systems, vol. 12, Sep. 2012, pp. 226-231, doi:10.5391/ijfis.2012.12.3.226.

[5] C. L. Chen and M. L. Chong , "A radio frequency identification application for car theft prevention in parking lot management systems," International Journal of Communication Systems, vol. 27, Nov. 2014, pp. 2481-2496, doi: 10.1002/dac.2482. 